\title{
Subcutaneous Immunotherapy With High-Dose Cat and Dog Extracts: A Real-life Study
}

\author{
Uriarte $\mathrm{SA}^{1}$, Sastre J1,2,3 \\ 'Department of Allergy, Fundación Jimenez Diaz, Madrid, Spain \\ ${ }^{2}$ CIBERES, Instituto Carlos III, Madrid, Spain \\ ${ }^{3}$ Department of Medicine, Universidad Autónoma de Madrid, Madrid, Spain
}

J Investig Allergol Clin Immunol 2020; Vol. 30(3): 169-174

doi: 10.18176/jiaci.0415

\begin{abstract}
Background: Data on the efficacy of immunotherapy administered to patients with cat or dog allergy are scarce. Objective:We aimed to evaluate the safety and efficacy of subcutaneous immunotherapy (SCIT) in patients with allergy to cat and dog dander. Methods: Consecutive patients with rhinitis and/or asthma related to sensitization to cat or dog dander were included in a pragmatic, real-life, prospective, observational study. All patients had specific lgE to cat, dog, or both. SCIT was administered using an infusion pump over 3 sessions as part of a rush protocol, followed by monthly administration over 12 months. We recorded adverse events, clinical outcomes, pulmonary function, FeNO, symptoms of rhinitis and asthma, quality of life (QoL), Asthma Control Test (ACT) score, and visual analog scale (VAS) score at baseline, 6 months, and 12 months.

Results: The study population comprised 66 patients (38 females, 46 allergic to cat and 20 to dog), with ages ranging from 9 to 59 years. During the up-dosing phase, in which the infusion pump was used, $8.1 \%$ of doses elicited a systemic reaction and $5.4 \%$ caused a local reaction, while $9.3 \%$ of doses administered during the maintenance phase (ie, without an infusion pump) induced a systemic reaction. No local reactions were recorded. A significant improvement in $\mathrm{FEV}_{1}$, symptoms of rhinitis and asthma, QoL, use of medication, VAS score, and ACT score was observed at 6 months and continued at 12 months. Clinical improvement with cat extract was significantly better than with dog extract.

Conclusions: High-dose SCIT has substantial clinical value in many cat- and dog-allergic patients.
\end{abstract}

Key words: Cat. Dog. Allergy. Rhinitis. Asthma. Allergen immunotherapy.

\section{Resumen}

Antecedentes: Hay pocos estudios sobre la eficacia de la inmunoterapia administrada a pacientes con alergia a perro o gato.

Objetivo: Evaluar la seguridad y la eficacia de la inmunoterapia subcutánea (SCIT) en pacientes con alergia a estos dos animales.

Métodos: Se incluyeron pacientes consecutivos con rinitis y/o asma relacionados con la sensibilización al gato o al perro en un estudio observacional prospectivo, pragmático, en vida real. Todos los pacientes tenían IgE específica para gato y/o perro. La SCIT se administró utilizando una bomba de infusión (IP), en 3 sesiones como parte de un protocolo rápido, seguido de la administración mensual durante 12 meses. Se recopilaron datos sobre efectos adversos y resultados clínicos, función pulmonar, FeNO, síntomas de rinitis y asma, calidad de vida (QoL), prueba de control del asma (ACT) y escala analógica visual (VAS) al inicio, a los 6 y 12 meses.

Resultados: Se incluyeron 76 pacientes: 38 mujeres, 46 alérgicos a gato y 20 a perro, con edades comprendidas entre los 9 y los 59 años. Durante la fase de administración ascendente, utilizando una IP, el 8,1\% de las dosis provocó una reacción sistémica (SR) y el 5,4\% causó una reacción local (LR), mientras que el 9,3\% de las dosis administradas durante la fase de mantenimiento (es decir, sin IP) desarrolló una $S R$, y no se registraron LRs. Se observó una mejoría significativa en el FEV ${ }_{1}$, en los síntomas de rinitis, de asma y en los cuestionarios de la calidad de vida, uso de medicación, VAS y ACT a los 6 meses y continuó a los 12 meses. La mejoría clínica con el extracto de gato fue significativamente mayor que con el perro.

Conclusiones: Las dosis altas de SCIT tienen un valor clínico sustancial en muchos pacientes alérgicos a perros y gatos.

Palabras clave: Gato. Perro. Alergia. Rinitis. Asma. Inmunoterapia con alérgenos. 


\section{Introduction}

Data on the efficacy of allergen immunotherapy in patients with cat allergy [1-9] or dog allergy $[3,5,10]$ remain scarce, especially in the case of dog allergy. High doses of standardized extracts have proven effective in treating patients who are allergic to cat. Previous double-blind studies with subcutaneous immunotherapy (SCIT) based on standardized cat allergen extracts have demonstrated that maintenance doses containing $13.2 \mu \mathrm{g}$ of Fel d 1 [6], $13.8 \mu \mathrm{g}$ of Fel d 1 [4], and $15 \mu \mathrm{g}$ of Fel d 1 [7,8] improved symptoms associated with exposure to cat and brought about immunologic changes [2,4,8,11-13]. SCIT with standardized dog allergen extract has proven less efficacious than SCIT with standardized cat allergen extract $[3,5,10]$, despite having induced immunologic changes $[12,14]$.

The purpose of the present study was to explore the use of high-dose SCIT in patients with allergic rhinitis and asthma caused by exposure to cat and dog dander in real-life clinical practice.

\section{Material and Methods}

\section{Patients}

We conducted a prospective observational study of consecutive patients with rhinitis and/or asthma due to sensitization to cat or dog dander and for whom treatment with immunotherapy was indicated [15]. All candidates for inclusion expressed a willingness to initiate SCIT after receiving information on the possible benefits of this approach. For a patient to be included, a strong association between clinical symptoms and exposure to cat or dog was required. An additional requisite was positive specific IgE to cat or dog extract as evidenced by the skin prick test (ALK, Denmark) and/or in serum and specific IgE to whole cat or dog extracts or to Fel d 1, Fel d 2, Fel d 4, Can f 1, Can f 2, Can f 3, and Can f 5 (ImmunoCAP or ISAC, Thermo Fisher Scientific). Patients or their guardians signed an informed consent document. The study was approved by the local ethics committee (FJDALG-15/01).

\section{Immunotherapy}

Immunotherapy with cat and dog extracts (Alutard SQ, Alk-Abelló) was administered at the following concentrations of major allergens: Fel d 1, $15 \mu \mathrm{g} / \mathrm{mL}$; Can f 1, $3.21 \mu \mathrm{g} / \mathrm{mL}$; Can f 5, $0.72 \mu \mathrm{g} / \mathrm{mL}[16]$.

Up-dosing consisted of 3 progressively increasing doses from the maintenance vials $(100000 \mathrm{SQ} / \mathrm{mL}$; ie, 10000 , 50 000, and $100000 \mathrm{SQ}$ ) administered at weekly intervals. Doses were administered using an infusion pump (Infusa T1, Medis), with infusions lasting 30 minutes, as previously described $[17,18]$. Patients were observed for 30 minutes after the infusion was complete. Subcutaneous injections were applied for monthly maintenance doses.

Adverse reactions (ARs) (local, systemic, immediate, or delayed) were recorded according to EAACI guidelines [15]. Delayed ARs were monitored by telephone interview 48 hours after SCIT; for this purpose, patients received instructions on how to monitor ARs if necessary. Patients were not routinely premedicated.

\section{Clinical Outcomes}

We performed spirometry and bronchodilation testing and measured the fractional exhaled nitric oxide (FeNO) concentration. We also administered a series of questionnaires validated for the Spanish population, as follows: ESPRINT-15 (health-related quality of life in allergic rhinitis), Asthma Quality of Life Questionnaire (AQLQ), Asthma Control Test (ACT), and a 10-cm visual analog scale (VAS) for assessment of nasal, ocular, and bronchial symptoms. Scores for nasal symptoms (itching, congestion, rhinorrhea, sneezing), ocular symptoms (tearing, itching, gritty sensation), and pulmonary symptoms (cough, wheezing, dyspnea, exercise-induced asthma) ( 0 , no symptoms; 1 , mild; 2 , moderate; 3 , severe) and use of medication were applied. Medication use was scored as follows: antihistamines, 6 points; short-acting $\beta_{2}$-agonists, 2 points; inhaled corticosteroids, 2 points; nasal topical corticosteroids, 2 points; and oral corticosteroids, 4 points. All assessments were performed at baseline and at 6 and 12 months.

To measure the response to SCIT, the minimum clinically important differences considered were as follows: ESPRINT-15, $>0.9$ [19]; AQLQ, $>0.5$ per dimensional item, with an average change of 1.0 considered moderate and a change of at least 1.5 considered large [20]; ACT $>3$ [21]; and VAS $>2$ between visits.

Associations between the IgE molecular profile and safety outcomes and the clinical efficacy of cat and dog extract were analyzed, as was the difference in the clinical efficacy of SCIT between cat and dog extract.

\section{Statistical Analysis}

The statistical analysis was based on the Fisher exact test, Wilcoxon test, Friedman test, Kruskal-Wallis test, and a mixedeffects model. $P$ values $<.05$ were considered significant.

\section{Results}

\section{Patients}

Sixty-six patients were included ( 38 females and 28 males, of whom 46 were allergic to cat and 20 to dog), with a mean age ranging from 9 to 59 years $(34.23$ [12.1]). Of these, $36.3 \%$ were sensitized to pollen, $4.1 \%$ to profilin, $6 \%$ to mites, and $6 \%$ to other allergens. Allergic rhinitis was present in 65 patients $(98.5 \%)$ and asthma in $64(97 \%)$. Most patients had persistent and moderate symptoms. Rhinitis was intermittent in $13.8 \%$, mild persistent in $21.6 \%$, and moderate/severe persistent in $64.6 \%$. Asthma was intermittent in $23 \%$, mild persistent in $36 \%$, and moderate/severe persistent in $41 \%$. Sixty-one patients $(92 \%)$ had either a dog or cat at home (daily direct contact), while $3(4.6 \%)$ had indirect contact with these animals, and $2(3 \%)$ were veterinarians.

Four patients dropped out of the study at the end of the up-dosing phase to continue their treatment in another center; a further 4 patients withdrew from the study between the third 
and sixth months ( 3 due to poor SCIT tolerance, 1 for personal reasons), and 7 patients between the sixth and twelfth month (all for personal reasons such as lack of time, distance from the hospital, travel abroad, and discontinuation of contact with pets). Fifty-one patients concluded the study (34 cat-allergic and 17 dog-allergic).

\section{Adverse Events}

During the up-dosing phase, 18 doses $(8.1 \%)$ of SCIT (all with cat extract) triggered a systemic reaction (SR), and 12 doses (5.4\%) produced a local reaction (LR); by comparison, 3 doses $(9.3 \%)$ administered during the maintenance phase caused an SR; no LRs were recorded. No SRs were triggered by doses of SCIT with dog extract in the up-dosing phase or in the maintenance phase (ie, with or without the infusion pump), and 2 doses (2.1\%) delivered using an infusion pump caused an LR, none of which occurred in the maintenance phase. ARs to SCIT tended to occur in patients with more severe asthma and poorer control, although this difference did not reach statistical significance.

The most frequent symptoms of SRs with SCIT based on cat extract were rhinitis (71.4\%) and asthma (71.4\%), followed by conjunctivitis (43\%) and urticaria (24\%). Most SRs were immediate $(90 \%)$ and grade $1(62 \%)$, and the rest were grade 2 (8 SRs). All SRs were controlled and resolved after treatment with antihistamines $(100 \%)$, inhaled $\beta_{2}$-agonists $(71 \%)$, systemic corticosteroids (47\%), and epinephrine (42.8\%). No cases of anaphylactic shock or hypotension were reported. The onset, grade, and treatment of SRs were similar in both the up-dosing phase and the maintenance phase. Onset was late and intensity mild in all LRs, and none required treatment. In total, 3 patients were withdrawn from the study owing to adverse events (all with cat extract).

\section{Specific $\lg E$}

All patients had a positive $\mathrm{IgE}$ level $(>0.35 \mathrm{kU} / \mathrm{L})$ and prick test result with cat and dog extracts. Among the cat-allergic patients, the results were positive for Fel d 1 in $83 \%$ of cases, Fel d 2 in 26\%, and Fel d 4 in 50\%. Among the dog-allergic patients, the results were positive for Can f 1 in $79 \%$, Can f 2 in $47 \%$, Can f 3 in $26 \%$, and Can f 5 in $63 \%$. In the case of dog-allergic patients, $21.1 \%$ were monosensitized to Can $\mathrm{f} 5$; none were monosensitzed to lipocalins or serum albumins. All dog-allergic patients recognized at least 1 commercially available allergen, while $12 \%$ of cat-allergic patients did not recognize any.

\section{Other Outcomes}

The results of the pulmonary function test, FeNO values, symptom scores, and the ACT, VAS, and medication scores are shown in Figure 1.

Baseline spirometry was normal in most patients with asthma, and the bronchodilation test did not reveal significant differences
A
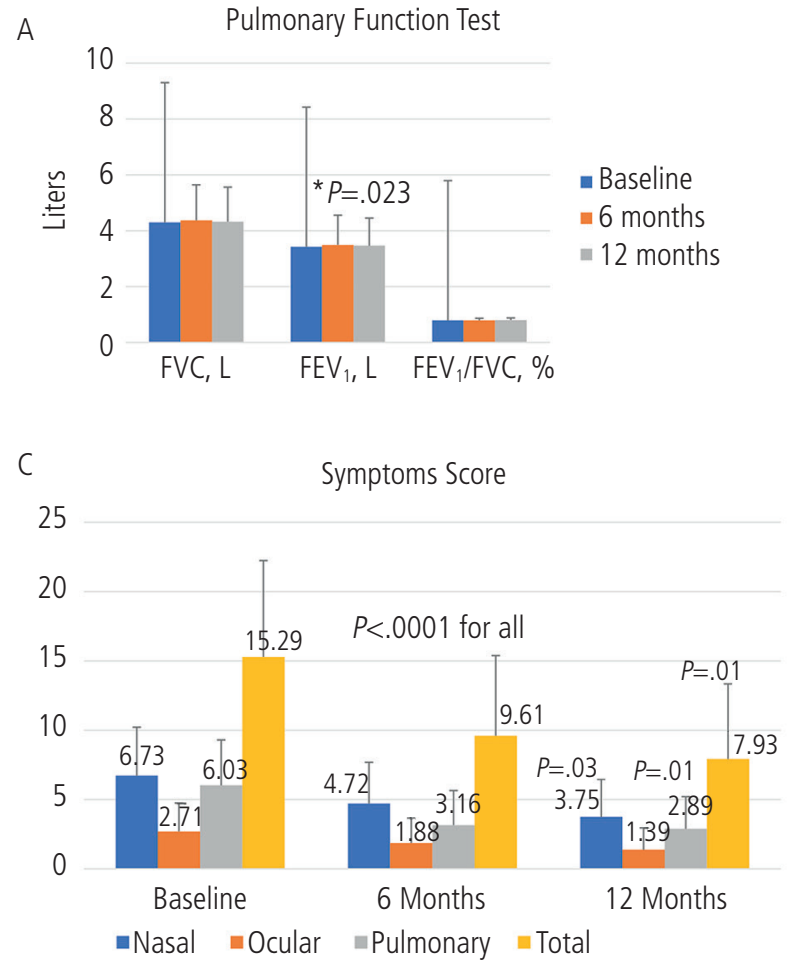

B

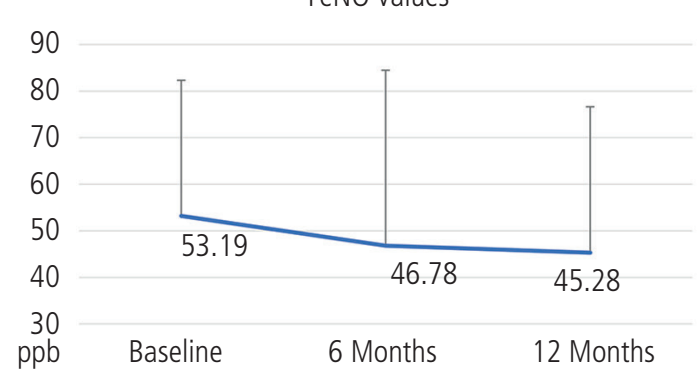

D

ACT-VAS-Medication Scores

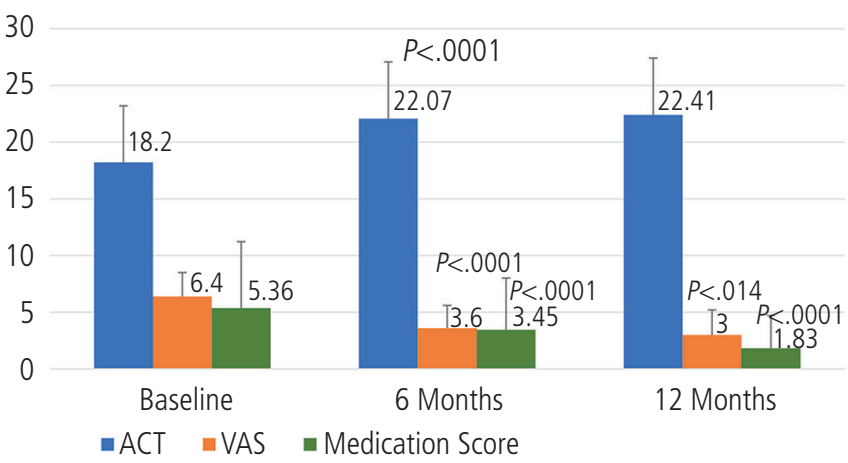

Figure 1. Results of pulmonary function test, FeNO values (in ppb), symptom scores, Asthma Control Test (ACT), visual analog scale (VAS), and medication scores. 
across the visits. $\mathrm{FEV}_{1}$ increased significantly at 6 months $(P=.023)$, but only by $50 \mathrm{~mL}$, which is not clinically relevant. Other spirometric values remained stable during the study.

At the beginning of the study, FeNO was elevated $(>50 \mathrm{ppb})$ in $77 \%$ of patients (47) and remained elevated at 6 months in $49 \%$ of patients (27) and at 12 months in $54.6 \%$ [30]. Mean FeNO values decreased by around $10 \%$ at the end of the study (Figure 1).

The mean increase in ACT score was 3.87 and 4.21 at months 6 and 12, respectively $(P<.0001$ for both from baseline), and in both cases the increase was greater than the minimal important difference (Figure 1).

The greatest decrease in medication use was seen with antihistamines and short-acting $\beta_{2}$-agonists. Doses of inhaled corticosteroids were approximately halved. No patient required systemic corticosteroids during the study (Figure 1).

The results of quality of life questionnaires for rhinitis and asthma are presented in Figure 2. The ESPRINT-15 questionnaire showed that $87.3 \%$ of patients improved at month 6 and that $80 \%$ maintained this improvement at month 12. The decrease in total score and all dimensions was greater than the minimal important difference (0.9).

At months 6 and 12, all dimensions of the AQLQ (activity limitation, symptoms, emotional function, environmental stimuli, and total) increased by more than 0.5 points, the minimal important difference; in many patients, this increase was more than 1 , which is considered a moderately important change. The AQLQ showed an overall improvement in $87 \%$ of patients in the first 6 months, with $83 \%$ maintaining the improvement at 12 months. The response to SCIT with cat and dog extract was good or very good in $66.7 \%$ of patients. Patients reported a subjective improvement with the third maintenance dose (month 2 of treatment).

The molecular profile (number of allergens to which the patients were sensitized or the quantitative value of specific IgE to allergens) was not related to the response to SCIT with cat or dog extracts $(P=.864)$ or with safety profile $(P=.109)$, FeNO values $(P=.592)$, direct contact with cats or dogs $(P=.39)$, age $(P=.218)$, or gender $(P=.697)$.
At the baseline visit, patients with dog allergy experienced a more deleterious impact on their quality of life in terms of asthma symptoms and emotional parameters $(P=.041$ and $P=.009$, respectively), required greater use of medication in general (especially inhaled corticosteroids $[P=.005]$ and antihistamines $[P=.006])$, and had higher FeNO values $(P=.001)$ and higher perceived symptom intensity (VAS). At the 12-month visit, the perceived intensity of symptoms remained unchanged $(P=.008)$. In addition, dog-allergic patients had an increased need for medication $(P=.02)$, poorer rhinitis-related quality of life in relation to their daily activities $(P=.042)$, and a lower $\mathrm{FEV}_{1} / \mathrm{FVC}$ ratio $(P=.049)$ than patients with cat allergy. The ACT scores at 6 and 12 months of treatment revealed a tendency toward improved disease course among patients receiving SCIT with cat extract than in those receiving SCIT with dog extract, although the differences were not statistically significant.

\section{Discussion}

Pragmatic trials provide information that may be considered complementary to data from randomized clinical trials [22]. This study, which was carried out in a real-life setting, confirms the efficacy of SCIT using extracts with high doses of dog and cat allergens. We administered immunotherapy using a rush up-dosing phase with an infusion pump followed by a monthly maintenance dose over a 12 -month period. The safety profile of the rush up-dosing and maintenance phases was generally good, as reported in previous studies using an infusion pump [17,18], conventional schedules [23], and other rush schedules [24], and the safety profile of the up-dosing and maintenance phases was even better than some cluster schedules described in the literature [5].

Systemic reactions to the SCIT were only observed with cat extract but not with dog extract, as reported elsewhere $[5,10]$. This extract-specific difference could be due to the high concentration of Fel d $1(15 \mu \mathrm{g})$, the major cat allergen, in comparison with the major dog allergens, Can $\mathrm{f} 1(3.21 \mu \mathrm{g})$ and
Rhinitis Quality of LIFE-ESPRINT-15 Score

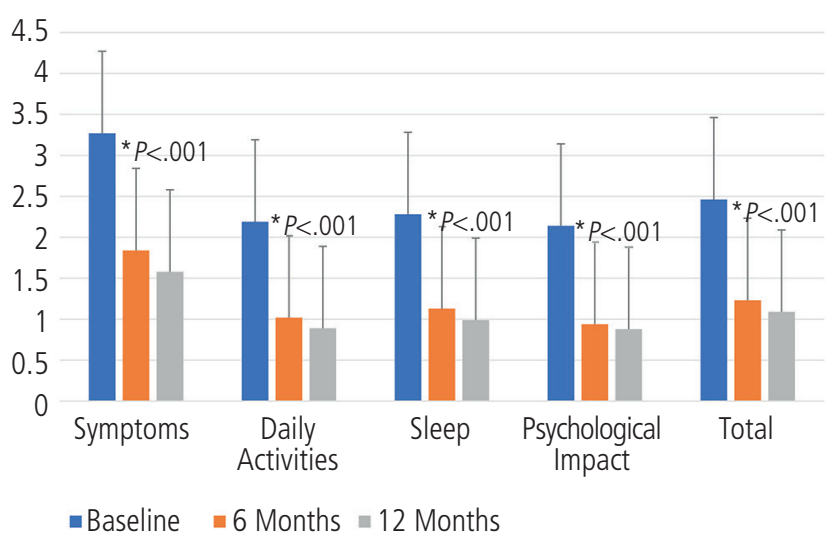

Asthma Quality of LIFE-AQLQ Score

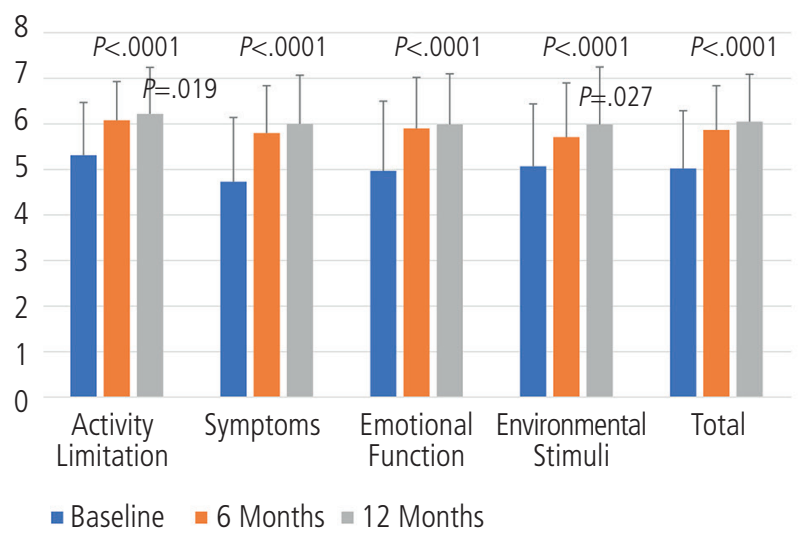

Figure 2. Results of quality of life questionnaires for rhinitis (ESPRINT-15) and asthma (AQLQ). 
Can f $5(0.72 \mu \mathrm{g})$ [16]. Most systemic reactions produced were grade 1 or 2 and resolved with appropriate treatment, although 3 patients withdrew from the study during the maintenance phase owing to adverse effects.

In this study and others published by our group [16,25], a high percentage of patients were monosensitized to Can $\mathrm{f} 5$. Can $\mathrm{f} 1$ and Can $\mathrm{f} 5$ were the most frequently recognized allergens in dog-allergic patients, followed by Can $\mathrm{f} 2$. In the case of cat-allergic patients, Fel d 1 was the most frequent, followed by Fel d 4 and Fel d 2 . Of note, $12 \%$ of cat-allergic patients had positive IgE to whole cat extract, although they did not recognize the 3 cat allergens tested, thus emphasizing the need for more allergens in clinical practice and the need to control the presence of whole allergens in diagnostic and treatment extracts. The pattern of allergen recognition was not associated with the onset of adverse events or efficacy of treatment.

SCIT with cat or dog extract showed clear clinical efficacy at 6 months, and this efficacy was maintained at 12 months of treatment. Throughout the study, significant improvements were observed in $\mathrm{FEV}_{1}$, rhinitis, AQLQ score, ACT score, VAS score, symptom score, and use of medication, even in cases where the patient maintained direct contact with the pet(s) at home. In addition, although the increase in $\mathrm{FEV}_{1}$ was not clinically relevant, the improvement in rhinitis and the test scores (AQLQ and ACT) exceeded the minimal important difference. Taylor et al [1], performed a double-blind placebo-controlled study with 10 cat-sensitized patients in which they recorded decreased bronchial and cutaneous sensitivity to cat extract in the group that received SCIT with cat allergen. Similar results have been reported elsewhere [2-4]. We recorded a less substantial improvement in ocular symptoms than in airway symptoms, thus contrasting with the studies by Alvarez-Cuesta et al [6] and Varney et al [7] (both with cat extract) and Valovirta et al [10] (with dog extract), who observed decreased conjunctival sensitivity throughout treatment.

Clinical efficacy differed based on the type of extract (cat or dog). The clinical improvement with cat extract was significantly more marked in terms of symptoms, use of medication, and lower $\mathrm{FEV}_{1} / \mathrm{FVC}$ ratio than with dog extract. Previous studies reported that SCIT with dog extract was less effective than SCIT with cat extract $[3,5,12,19,26]$, likely owing to the higher concentration of Fel d 1 than of Can $f 1$ or Can $f 5$ [16], even using concentrations recommended in the USA (ie, $15 \mu \mathrm{g} / \mathrm{mL}$ of Can f 1 per dose) [26]. Specific IgG and IgG4 to cat and dog allergens were not measured in this study. However, a significant immune response in the form of increased $\mathrm{IgG}$ and/or IgG4 titers to cat $[4,8,12,13,19]$ and $\operatorname{dog}[10,12,14]$ dander has been reported with extracts that were similar to those used in our study (Alutard SQ). The good clinical and immune response to SCIT is clearly associated with the high doses of major allergens contained in the extracts, mainly in the case of cat $[3-8,13,18,19]$.

Our study is limited by the modest number of patients and the lack of a placebo-control group. However, it was designed as a pragmatic trial. In addition, it is difficult to confirm our results, since we did not perform nasal or bronchial challenge or assess changes in skin reactivity.

\section{Conclusions}

This real-life study reinforces the clinical efficacy of SCIT with high-dose extracts in cat- and dog-allergic patients. The safety and efficacy profile of this SCIT regimen with cat or dog extract was not related to the molecular profile of $\operatorname{IgE}$.

\section{Acknowledgments}

We are grateful to Ignacio Mahillo and Francisco López for the statistical analysis and to Oliver Shaw, $\mathrm{PhD}$ for editorial assistance.

\section{Funding}

The study was partly funded by ALK, Madrid, Spain.

\section{Conflicts of Interest}

JS reports having served as a consultant to Thermo Fisher Scientific, MSD, Novartis, Genentech, Sanofi, Leti, Roche, ALK, FAES FARMA, Mundipharma, and GSK. He has also been paid lecture fees by Novartis, GSK, Stallergenes, LETI, and FAES FARMA and has received grant support for research from Thermo Fisher Scientific, ALK, and Sanofi.

SU and MJR declare that they have no conflicts of interest.

\section{References}

1. Taylor WW, Ohman JL Jr, Lowell FC. Immunotherapy in catinduced asthma. Double-blind trial with evaluation of bronchial responses to cat allergen and histamine. J Allergy Clin Immunol. 1978;61:283-7.

2. Ohman JL Jr, Findlay SR, Leitermann KM. Immunotherapy in cat-induced asthma. Double-blind trial with evaluation of in vivo and in vitro responses. J Allergy Clin Immunol. 1984; 74:230-9

3. Sundin B, Lilja G, Graff-Lonnevig V, Hedlin G, Heilborn $H$, Norrlind $K$, et al. Immunotherapy with partially purified and standardized animal dander extracts. I. Clinical results from a double-blind study on patients with animal dander asthma. J Allergy Clin Immunol. 1986;77:478-87.

4. Van Metre TE, Marsh DG, Adkinson NF, Kagey-Sobotka A, Khattignavong A, Norman PS Jr, et al. Immunotherapy for cat asthma. J Allergy Clin Immunol. 1988;82:1055-68.

5. Haugaard L, Dahl R. Immunotherapy in patients allergic to cat and dog dander. I. Clinical results. Allergy. 1992;47:249-54.

6. Alvarez-Cuesta E, Cuesta-Herranz J, Puyana-Ruiz J, CuestaHerranz C, Blanco-Quirós A. Monoclonal antibody-standardized cat extract immunotherapy: risk-benefit effects from a doubleblind placebo study. J Allergy Clin Immunol. 1994;93:556-66.

7. Varney VA, Edwards J, Tabbah K, Brewster H, Mavroleon G, Frew AJ. Clinical efficacy of specific immunotherapy to cat dander: a double-blind placebo-controlled trial. Clin Exp Allergy. 1997;27:860-7.

8. Ewbank PA, Murray J, Sanders K, Curran-Everett D, Dreskin S, Nelson HS. A double-blind, placebo-controlled immunotherapy dose-response study with standardized cat extract. J Allergy Clin Immunol. 2003;111:155-61. 
9. Williams AA, Cohn JR, Fung SM, Padams P. The efficacy of allergen immunotherapy with cat dander in reducing symptoms in clinical practice. Biomed Res Int. 2013;2013:324207.

10. Valovirta $E$, Koivikko A, Vanto $T$, Viander $M$, Ingeman L. Immunotherapy in allergy to dog: a double-blind clinical study. Ann Allergy. 1984;53:85-8.

11. Ohman JL Jr, Marsh DG, Goldman M. Antibody responses following immunotherapy with cat pelt extract. J Allergy Clin Immunol. 1982;69:320-6.

12. Hedlin G, Graff-Lonnevig V, Heilborn H, Lilja G, Norrlind K, Pegelow KO, et al. Immunotherapy with cat- and dog-dander extracts. II. In vivo and in vitro immunologic effects observed in a 1-year double-blind placebo study. J Allergy Clin Immunol. 1986;77:488-96.

13. Nanda A, O'connor M, Anand M, Dreskin SC, Zhang L, Hines B, et al. Dose dependence and time course of the immunologic response to administration of standardized cat allergen extract. J Allergy Clin Immunol. 2004;114:1339-44.

14. Lent AM, Harbeck R, Strand M, Sills M, Schmidt K, Efaw B, et al. Immunologic response to administration of standardized dog allergen extract at differing doses. J Allergy Clin Immunol. 2006;118:1249-56.

15. Zuberbier T, Bachert C, Bousquet PJ, Passalacqua G, Canonica GW, Merk $\mathrm{H}$, et al. GA²LEN/EAACl pocket guide for allergenspecific immunotherapy for allergic rhinitis and asthma. Allergy. 2010;65:1525-30.

16. Uriarte SA, Sastre J. Safety of an ultrarush (4 hours), subcutaneous immunotherapy with cat and dog extracts using an infusion pump. J Inves Allergol Clin Immunol. 2018;28:430-2

17. Uriarte Obando SA, Sastre Domínguez J. Safety of rush subcutaneous immunotherapy administered in real life using an infusion pump. Ann Allergy Asthma Immunol. 2015;115:527-9.

18. Sastre J, Vallejo L, Fernandez-Nieto M, Hernandez E, Rico P. Rush Allergen Subcutaneous Immunotherapy Administered with Infusion Pump. Ann Allergy Asthma Immunol. 2011;107:459-60.

19. Valero A, Izquierdo I, Sastre J, Navarro AM, Baró E, MartíGuadaño E, et al. ESPRINT-15 questionnaire (Spanish version): reference values according to disease severity using both the original and the modified ARIA classifications. J Investig Allergol Clin Immunol. 2013;23:14-9.

20. Juniper EF, Guyatt GH, Willan A, Griffith LE. Determining a minimal important change in a disease-specific Quality of Life Questionnaire. J Clin Epidemiol. 1994;47:81-7.

21. Schatz M, Kosinski M, Yarlas AS, Hanlon J, Watson ME, Jhingran P. The minimally important difference of the Asthma Control Test. J Allergy Clin Immunol. 2009;124:719-23

22. Roland M, Torgerson DJ. What are pragmatic trials? BMJ. 1998;316:285

23. Bertelsen A, Andersen JB, Christensen J, Ingemann L, Kristensen T, Ostergaard PA. Immunotherapy with dog and cat extracts in children. Allergy. 1989;44:330-5.

24. Lilja G, Sundin B, Graff-Lonnevig V, Hedlin G, Heilborn H, Norrlind $K$, et al. Immunotherapy with cat- and dog-dander extracts. IV. Effects of 2 years of treatment. J Allergy Clin Immunol. 1989;83:37-44.

25. Uriarte $S A$, Sastre J. Clinical relevance of molecular diagnosis in pet allergy. Allergy. 2016;71:1066-8.

26. Smith DM, Coop CA. Dog allergen immunotherapy: past, present, and future. Ann Allergy Asthma Immunol. 2016;116:188-93.

Manuscript received March 24, 2019; accepted for publication May 7, 2019.

\section{- Joaquín Sastre}

Department of Allergology

Hospital Fundación Jimenez Diaz

Avda. Reyes Católicos 2

28040 Madrid, Spain

E-mail: jsastre@fjd.es 